\title{
ARTE NA EDUCAÇÃO FUNDAMENTAL: QUAL A SUA IMPORTÂNCIA?
}

\author{
Débora Sanches Borges, Albertina Krawulski
}

Faculdade Norte Paranaense - UNINORTE. E-mail: deborasanchesborges@hotmail.com.

\section{RESUMO}

Este estudo visa ressaltar a importância da arte durante a educação fundamental, além de suas contribuições frente ao processo de ensino aprendizagem das crianças desta faixa etária. 0 problema de pesquisa que norteou o interesse para desenvolver tal material foi: Por que em nosso cotidiano a arte está perdendo sua importância frente à educação? Com o intuito de chegar a possíveis resultados, sobre esta indagação, realizamos uma pesquisa qualitativa, utilizando um questionário composto por questões estruturadas, além de nos pautarmos em referenciais teóricos. Compreendemos que a arte é vista e sentida de formas distintas em nossa sociedade e por aqueles que dela fazem parte, porém afirmamos que com o auxílio desta disciplina conseguimos formar cidadãos críticos e que saibam expressar seus desejos, anseios e acima de tudo seus sentimentos, levando em consideração suas ideias, sem aceitar os modelos preestabelecidos e impostos pela sociedade que aí está. Em suma, no decorrer desta pesquisa explanamos sobre a importância e os benefícios da arte na educação fundamental, visando o desenvolvimento da expressão criadora, questionando e salientando o papel do professor frente a este desenvolvimento de ensino e aprendizagem, diante de uma disciplina que julgamos ser essencial para o desenvolvimento educacional e pessoal das crianças.

Palavras-chave: Arte; Educação; Benefícios; Cidadãos.

\begin{abstract}
This study aims to highlight the importance of art education for the fundamental, well ahead of his contributions to teaching and learning process of children in this age group. The research problem that has guided us to develop such a material interest is: Why in our everyday art is losing its importance to education front? In order to arrive at possible outcomes on this question, we conducted a qualitative study using a questionnaire consisting of structured questions, in addition to the theoretical pautarmos. We understand that art is seen and felt in different ways in our society and those who are part of it, but stated that with the help of this discipline can form and critical citizens who can express their desires, aspirations and above all his feelings, leading into consideration their ideas without accepting predetermined models and imposed by society that there is. In short, during this study will explain about the importance and benefits of art in elementary education, aiming at the development of creative expression, questioning and stressing the role of the teacher in the face of this development of teaching and learning, a discipline before we judge be essential to the educational and personal development of children.

Keywords: Art; Education, Benefits, Citizens.
\end{abstract}




\section{INTRODUÇÃO}

O intuito desta pesquisa é ressaltar a importância da arte dentro da educação fundamental, fazendo-se necessário por parte do educador: “[...] ver a arte não apenas como uma das metas da educação, mas sim como o seu próprio processo, que é considerado também criador [...]". (FERRAZ; FUSARI, 2010, p.15).Por meio desta visão, poderá vir a ser proporcionada ao aluno, a motivação necessária para que ele venha a adquirir um conhecimento artístico e o interesse pela disciplina em questão, uma vez que acreditamos ser a arte um dos itens essenciais, em cada fase do desenvolvimento dos educandos.

De acordo com os PCN'S (1997, p. 35):

O ensino fundamental configura-se como um momento escolar especial na vida dos alunos, porque é nesse momento de seu desenvolvimento que eles tendem a se aproximar mais das questões do universo do adulto e tentam compreendê-las dentro de suas possibilidades. Ficam curiosas sobre temas como a dinâmica das relações sociais, as relações de trabalho, como e por quem as coisas são produzidas.

Desde os primórdios da civilização temos influências artísticas, o que pode ser notado dentro de nosso cotidiano, pois: “[...] umas das primeiras referências da existência humana na Terra aparece nas imagens desenhadas nas cavernas, que atualmente são chamadas de imagens artísticas [...]".Buoro (2006, p. 20). Propomos então aos educadores, que a arte seja não a base, mas um dos alicerces da Educação Fundamental visto a mesma estar relacionada à visão de mundo que o educando traz para a escola. Acreditamos também, que a disciplina de arte seja desenvolvida, dando-se a ela a mesma importância que se dá às demais disciplinas.

De acordo com Lowenfeld e Brittain (1970, p.15):

Não queremos dar a impressão de que a humanidade é salva pelo mero desenvolvimento de um bom programa de criação artística, nas escolas públicas; mas os valores significativos num programa de arte são os mesmos que podem ser básicos para o desenvolvimento de uma nova imagem, de uma nova filosofia e mesmo de uma estrutura inteiramente nova do nosso sistema educacional [...] O processo de aprendizagem é muito complexo e, portanto, talvez não exista um único processo de ensino que possa considerar "o melhor". 
Compreendemos que a arte é vista e sentida de formas diferentes por crianças e adultos, uma vez que crianças utilizam a arte para expressar seus sentimentos e emoções, enquanto o adulto se foca na beleza do trabalho artístico. Lowenfeld e Brittain (1970, p.19) ressaltam que a arte:

[...] para o adulto, ela está
usualmente associada à
área da estética, da beleza
externa. Para a criança, a
arte é algo muito diferente
e constitui
primordialmente, um meio
de expressão. [...] A criança
é um ser dinâmico; para ela,
a arte é uma comunicação
do pensamento. [...] Dessa
discrepância entre gosto
adulto e o modo como à
criança se expressa surge à
maioria das dificuldades
que impedem as crianças
de usar a arte como
verdadeiro meio de auto-
expressão.

\section{O ENSINO DE ARTE NA EDUCAÇÃO}

FUNDAMENTAL: CONSIDERAÇÕES E

\section{RELEVÂNCIA}

Pode-se afirmar que o homem procura registrar momentos históricos de sua cultura e sociedade, por meio da arte, seja em forma de escultura, pintura, retrato, música, ou qualquer outro elemento artístico. Isso porque busca transformar a experiência vivida em algo que evidencie assim seu momento histórico: "O homem tenta satisfazer suas necessidades socioculturais por meio de sua arte, o que ocorre em cada momento específico e em cada cultura". (BUORO, 2003, p. 30).

Contudo, mesmo a arte tendo sido vivenciada por povos primitivos, seu reconhecimento como uma disciplina a ser trabalhada durante o processo de formação da criança demorou a ocorrer: "Embora o trabalho artístico seja tão antigo quanto à própria educação, seu reconhecimento, como fator de educação, é relativamente recente". (SOUZA, 1968, p.45). A autora ainda afirma que:

Numa época em que não encontrara, ainda, um processo de transmitir e perpetuar suas idéias, por meio de linguagem escrita, já o Homem traduzia suas experiências de vida através da atividade criadora e por força de sua criação artística [...]. (SOUZA, 1968, p.47).

O ensino da arte segundo Barbosa (1994, p. 25), deve seguir uma: “[...] Metodologia Triangular que é composta pela História da Arte, pela leitura da obra de arte e pelo fazer artístico [...]", ou seja, é de suma importância para o aluno que aprende arte, saber não apenas fazer algo, mas também reconhecer de onde veio o que ele está aprendendo e fazendo, refletindo sobre o que levou o artista a desenvolver tal obra para, assim, vir a fazer uma leitura sobre a obra, percebendo a mensagem ali explícita, 
vivenciando o que o artista deseja remeter para a sociedade. Sendo assim, podemos resumir a proposta triangular em: aprender, apreciar e fazer.

Atualmente, o ensino de Arte é diversificado, não sendo voltado apenas para o desenho geométrico ou Artes Plásticas, uma vez que envolve outras linguagens artísticas como, a dança, a música e o teatro, que muito enriquecem a formação dos educandos.

Notamos nos dias atuais, que a proposta de trabalho para esta disciplina é um tanto quanto precária, sendo utilizada apenas como complemento à outra, ou ainda como momento de distração e lazer das crianças. Conforme os benefícios descritos anteriormente, vale ressaltar que a arte é relevante no dia a dia das crianças, vindo a mesma a proporcionar e colaborar com o desenvolvimento de sua autoexpressão, possibilitando assim expressar seus sentimentos e criatividade, desenvolvendo a capacidade de sensibilização, trabalho e desenvolvimento a partir de situações diversas, que ocorrem no seu contexto social podendo assim visualizar o mundo com outros olhos, vindo estes a encontrarem soluções para problemas oriundos de um olhar sem arte, sem vida e sem humanização. Desta forma concordamos com Coleto (2010, p.138 139), quando afirma:
[...] Os seres humanos são dotados de criatividade e possuem a capacidade de aprender e de ensinar. A criatividade da criança precisa ser trabalhada e desenvolvida e é por meio do trabalho realizado com a arte nas escolas que isso será possível. [...] a arte ainda não é ensinada e aprendida de uma maneira suficiente para a maioria de crianças e adolescentes brasileiros. É necessário um espaço para o desenvolvimento pessoal e social por meio de vivência e posse de conhecimento artístico e estético do aluno, e para isso é preciso pensar uma nova metodologia.

De outro prisma, compreendemos que cabe ao professor, como mediador do conhecimento, desenvolver métodos que possibilitem um estudo elaborado dos elementos artísticos, desenvolvendo a capacidade de nossos educandos em buscar, investigar e descobrir respostas, ao invés de aguardar a vinda de informações, respostas e modelos prontos estabelecidos pelo professor, visando ainda à importância de o docente ter um referencial frente à disciplina em questão, além de metodologias maleáveis que atendam a necessidade de sua turma.

$\mathrm{Na}$ contemporaneidade, vemos $\mathrm{O}$ homem se transformar em um mero espectador dos elementos artísticos, um consumidor passivo, esperando e absorvendo 
tudo o que lhe é imposto, observa-se em nossa sociedade músicas servindo de fundo em lojas, a televisão cada vez menos informando algo cultural, apenas transmitindo cenas inadequadas para crianças, apenas citando aqui como exemplo, os desenhos que retratam monstros e destruições. Para tanto observamos que o ser humano: "está-se convertendo num espectador passivo da sua cultura, em vez de seu construtor ativo." (LOWENFELD; BRITTAIN, 1970, p.23).

Os PCN'S (1997, p. 37) destacam a atenção que se faz necessária no tocante à arte, quando menciona:

[...] nem sempre se
apresenta no cotidiano
como obra de arte. Mas
pode ser observada na
forma dos objetos, no
arranjo de vitrines, na
música dos puxadores de
rede, nas ladainhas
entoadas por tapeceiras
tradicionais, na dança de
rua executada por meninos
e meninas, nos pregões de
vendedores, nos jardins, na
vestimenta, etc. [...].

Contudo, visamos ressaltar que o ensino da arte necessita e merece uma maior atenção por parte de nossa sociedade e por dos gestores escolares, visto a mesma poder vir a proporcionar inúmeros benefícios para o desenvolvimento dos educandos, não apenas dentro da escola, mas em toda a sua vida, já que esta disciplina engloba temas transversais. Cabe ao educador no papel de mediador do conhecimento, proporcionar experiências que estimulem e propiciem tais desenvolvimentos, e desta forma levar seus alunos à concepção do que é arte e quais desenvolvimentos ela pode lhes proporcionar.

Quando nos referimos aos temas transversais, estamos tratando de temas que abrangem a sociedade, levando os alunos da educação fundamental a refletir sobre seus princípios e valores, ou seja, de acordo com os PCN'S (1997, p. 25):

O conjunto de temas aqui proposto (Ética, Meio Ambiente, Pluralidade Cultural, Saúde e Orientação Sexual) recebeu o título geral de Temas Transversais, indicando a metodologia proposta para sua inclusão no currículo e seu tratamento didático.

Deste modo, a arte pode ser associada a qualquer atividade que venha a ser executada no processo de ensino aprendizagem, proporcionando desenvolvimentos significativos para as crianças, o que iremos abordar no decorrer desta pesquisa.

Percebe-se que muitas vezes durante a educação fundamental, acabamos interferindo na atividade artística e criadora da criança, pois em nosso pensamento, historicamente tradicionalista, achamos que 
podemos intervir e que somos conhecedores de sentimentos e sensações. Por exemplo, quando uma criança solta rabiscos desordenados em uma folha de papel, sempre a questionamos sobre o que desenhou, e muitas vezes interferimos no processo de criação, acreditando que ela ainda não estabeleceu o que será sua criação, e que está apenas procurando firmeza em seus traços.

Observamos que muita criança em uma aula de arte diz que não sabe desenhar, mas o que se deve levar em consideração é que mesmo um rabisco é uma forma de arte, é uma formação de expressão, e que este momento didático não é apenas um momento para aprender a desenhar e colorir, mas sim um momento de libertação da imaginação por parte da criança, através de um simples rabisco em uma folha de papel, esta criança tomará consciência que tem o poder e a capacidade de criar.

Muitos professores da educação fundamental cometem grandes erros ao tentar ajudar as crianças a desenhar. Uma forma não tão apropriada de ajudar as crianças é quando mostramos como desenhar algo, pois desta forma impomos nossa imaginação adulta para a criança que ainda está construindo a sua, além de estarmos inibindo a expressão criadora delas. Segundo Lowenfeld a melhor forma de ajudar uma criança em uma atividade artística é motivando suas expressões e criações.

Não se deve confundir motivação com elogios, ou seja, não é correto elogiar tudo o que a criança faz, já que o elogio apenas distribuído anula o seu valor e a criança se acostuma a ele. Elogios devem ser utilizados, para estimular a criança, aumentando a sua confiança durante a realização da arte e de sua atividade criadora.

No processo, a crítica e o elogio se farão presentes, mas nunca devem ser sobre a forma de como a criança realiza alguma atividade e sim referente ao que se criou, para que estes métodos venham a ser construtivos e não de desmotivação, lembrando também que nem sempre o que nos agrada é do agrado das crianças.

Sendo assim para compreendermos a importância da disciplina, devemos sempre ter a noção de que adultos e crianças têm visões, sentimentos e idéias distintas referente à arte. $\mathrm{O}$ adulto se prende a beleza, enquadrando-se ao modelo da sociedade, já a criança busca a arte para expressar seus sentimentos, e nós adultos acabamos por moldá-las ao padrão da sociedade, afirma Coleto (2010, p.139).

Compreende-se então, que a criança desenha de acordo com suas vivências e experiências (conhecimento de mundo), e que isso faz parte do progresso emocional por que passa cada sujeito. Esta questão fica 
confirmada por (LOWENFELD; BRITTAIN, 1970, p. 40), quando dizem que para a criança: "[...] a experiência artística é realmente sua, e a intensidade de sua absorção proporciona-lhe o verdadeiro progresso emocional".

Ajudar as crianças a desenvolver relações de auto-expressão em suas produções, auxiliando-as e motivando-as, não significa que iremos criar ótimos artistas, mas sim que estamos favorecendo seu processo de desenvolvimento intelectual.

\section{CONCLUSÃO}

Os trabalhos artísticos das crianças podem revelar muitas coisas, desde o desenvolvimento de sua capacidade criadora até a exteriorização de seus desejos, além da simples imagem, ou do produto confeccionado, pois ao realizar qualquer trabalho a criança deposita ali sua visão de mundo, seus desejos e anseios, sem receio, pois para ela a arte é mais do que um momento de distração, sendo desta forma um meio de comunicação, tanto consigo mesma, como com o meio que a cerca. 0 ensino da arte se torna fascinante, quando observamos a forma com que as crianças se expressam, quando buscamos compreender como elas retratam o seu meio, seus sentimentos e suas vivências de mundo. Concordamos com Holm (2004, p. 160) Correção, não consta referência desta citação: “Uma tarefa criativa brilhante é aquela que faz o aluno pensar para além dos limites dados, ou quebrar as fronteiras".

Muitos educadores pensam que o mais importante para o desenvolvimento de uma aula de arte é a escolha de um prédeterminado tema, porém nesta disciplina esta escolha possui um significado que se difere das demais disciplinas, Lowenfeld e Brittain (1970, p. 51), afirmam:

Nas experiências artísticas não existe um tema para ser ensinado. $\mathrm{O}$ mesmo conteúdo temático é usado pelas crianças muito pequenas e pelos artistas profissionais. Um homem pode ser desenhado por uma criança de cinco anos ou por um jovem de dezesseis. A diferença entre os dois desenhos não reside no tema, mas sim na maneira como este é representado.

Assim, concluímos que, a partir de uma aula bem planejada, que envolva a arte, será possível permitir a criança fazer amigos, aprender as regras de convivência além das regras sociais, respeitar os outros e buscar soluções para a resolução de problemas, sendo que a arte engloba diversos desenvolvimentos no processo de formação das crianças conforme já citamos anteriormente, e ainda, desenvolve a autonomia, a criatividade e a cooperação destes educandos. 
Ao realizarmos um questionário com alguns professores da educação fundamental da rede pública de nossa cidade e após analisá-los, juntamente a nossos embasamentos teóricos, chegamos à conclusão de que, havendo o estímulo por parte do professor este atuando como mediador no processo de ensino, poderá ocorrer uma evolução quanto à expressão artística e criadora das crianças frente à aprendizagem de novos conhecimentos, este tratando-se da interdisciplinaridade educacional.

Esta disciplina contribui para o desenvolvimento de diferentes competências de cada ser humano, pois as representações artísticas possíveis a serem realizadas em uma sala de aula, refletem o modo de pensar e agir do educando e ainda como este produz e organiza seus pensamentos. Com isto a arte se faz presente na construção e formação da identidade pessoal de cada educando durante a educação fundamental.

Em muitos casos analisamos que os professores deixam de utilizar atividades artísticas e criadoras em sua prática docente, por considerar não possuir aptidão para a desenvoltura de tais atividades. Isto ocorre porque este educador se corrompeu entregando-se o padrão de beleza preestabelecido pela sociedade que habita ou ainda, por que se trata de um educador estacionário, que não visa o progresso, que não busca uma formação continuada para sua carreira, apenas transmitindo, transformando seus alunos em uma conta bancária onde somente transfere ou deposita seus conhecimentos.

Em síntese, concluímos que a arte está presente no mundo deste a existência do homem, porém com o passar do tempo, o ser humano está perdendo sua sensibilidade, fechando os olhos para tal disciplina, pois este se acomoda e aceita o padrão de beleza preestabelecido pela sociedade que o cerca, deixando de exercer seu papel como cidadão, principalmente de formar seus próprios desejos e anseios, perdendo então a sua identidade.

Podemos então concluir que, uma pessoa ao possuir domínio artístico não se deixará abater por qualquer problema, tendo sempre um olhar criador e inovador para enfrentar a situação que the remete dificuldade. Será neste momento, quando ao conseguir ultrapassar tal situação que compreenderá que isso só foi possível, por possuir criatividade e visão de mundo frente ao que foi enfrentado.

A arte, não se resume em atividades de pintura ou criação de objetos de decoração, menos ainda como momento de distração. Esta disciplina também engloba diversos itens necessários para o bom desenvolvimento físico e mental de nossos alunos, desenvolvimentos estes de suma 
importância dentro do processo de ensinoaprendizado. Necessário se faz então, que haja um comprometimento por parte de cada educador para que a disciplina de Arte seja bem utilizada dentro da Educação Fundamental, transformando esta em uma disciplina auxiliadora, dentro do processo de aprender e apreender as demais disciplinas.

\section{REFERÊNCIAS}

BARBOSA, A. M.. A imagem no ensino da arte: anos oitenta e novos tempos. São Paulo: Perspectiva, 1994.

BRASIL. MEC/SEF. Parâmetros Curriculares

Nacionais: Arte. Brasília, 1997.

COLETO, D. C.. A importância da arte para a formação da criança. São Paulo: Capivari, 2010. (Revista Conteúdo volume 3).

FERRAZ, Maria Heloisa Correa de Toledo. FUSARI, Maria F. de Rezende. Arte na Educação Escolar. São Paulo: Cortez, 2010.

HOLM, Anna Marie. Fazer e Pensar Arte. São Paulo: Museu de Arte Moderna, 2004.

LOWENFELD, V.; BRITTAIN, W. L. Desenvolvimento da capacidade criadora. São Paulo: Mestre Jou, 1970.

SOUZA, A M. Artes Plásticas na Escola. Rio de Janeiro: Bloch, 1968.

Recebido para publicação em 22/11/2011

Revisado em 06/05/2013

Aceito em 23/05/2013 